\title{
Influence of Exposure to Children's Movies on Television on Theory-of- Mind Acquisition in Preschoolers
}

\author{
Devi Rusli \\ Faculty of Science Education, Psychology Department, Universitas Negeri Padang, 25131, Sumatera Barat, \\ Indonesia \\ Corresponding author email: devirusli@fip.unp.ac.id
}

Dian Novita Ariani

Faculty of Psychology, University of Indonesia, Depok, Indonesia

Email:dianofitariani@gmail.com

\author{
Nurmina \\ Faculty of Science Education, Psychology Department, Universitas Negeri Padang, Padang, 25131, Sumatera \\ Barat, Indonesia \\ Email: nurminadavy.psi@gmail.com

\section{Rinaldi} \\ Faculty of Science Education, Psychology Department, Universitas Negeri Padang, Padang, 25131, Sumatera \\ Barat, Indonesia \\ Email: naldipsi@fip.unp.ac.id
}

\begin{abstract}
Recently cases of harness which are conducted by children indicated that decrease capability of children understanding against other's mental states Children's ability to grasp other's mental states (theory of mind) is important in the context of socialization. Previous research has not investigated the duration in measuring the exposure of narrative media (children's movies on television), which is one of the impacts on the acquisition of ToM. The movie on television represents the relations between children and their mental state. This study aims to investigate the influence of exposure to children's movies on television towards children's ToM acquisition among preschoolers. ToM was assessed using a ToM scale by Wellman and Liu, and exposure to children's movies on television was measured with a questionnaire. The study has been conducted on 85 preschoolers ages 3-5 years old/36-71 months $((M=4.88 S D=0,683)$, with the involvement of their parents to fill the questionnaires. The result of this study shows that exposure to children's movies on television does not significantly influence children's ToM. The strong relations between the two are considered false belief (FB) since the result of the study shows that.
\end{abstract}

Keywords---children, movies, preschoolers, television, theory-of-mind.

\section{Introduction}

Reporting from the website of kpai.go.id, 2020, the Indonesian Child Protection Commission in 9 years (2011-2019) recorded the number of cases of violence against children reaching 37,381. In early 2020 (January-February) there were reports of 2,473 cases of bullying in children that occurred in the school environment and on social media. The bully is generally done by his friends. This indicates that the lower the child's empathy for others (peers). Research results by Flavell and Miller; Cutting and Dunn (Flavel \& Miller, 1998; Cutting \& Dunn, 1999) found that empathy is related to children's ability to understand other people's mental situations (desires, thoughts, beliefs, and feelings). Mental situations can cause psychological stress and affect feelings (Suhron et al, 2019; Yusuf, 2019; Suhron et al., 
2020; Marasabessy \& Suhron, 2020).

The ability of children to understand other people's mental situations in developmental psychology is known as the theory of mind (Wellman \& Liu, 2004; Bloom \& German, 2000; Baron-Cohen et al., 1985). This condition can affect a person's self-esteem (Suhron, 2016; 2017). Some experts say the theory of mind (hereinafter abbreviated to ToM) is a natural talent possessed by humans, but some other experts say that ToM is obtained from the results of socialization such as nurture, the presence of siblings, and others. Due to the influence of socialization factors, the achievement of ToM in children varies. According to experts an understanding of the mental situation of others is obtained from an early age, the ability of ToM experiences rapid development at the age of 3-5 years (Shahaeian, 2011; Wellman et al., 2001; Wimmer \& Perner, 1983; Astington, 1995).

The ToM concept has developed over time. 1983 Wimmer and Perner measured ToM abilities in preschool children using false beliefs. This concept aims to determine children's understanding of other people's beliefs that are wrong or not the same as real reality. Furthermore, in 2004, Wellman and Liu measured ToM using five concepts known as the ToM scale. The ToM scale is used to determine children's understanding of the concept of diverse desire (DD), namely understanding the desires of different people, the concept of diverse beliefs (DB), namely understanding the beliefs of different people, the concept of knowledge access (KA), namely understanding of knowledge other people based on known information, the concept of false beliefs (FB), namely the wrong understanding of other people's beliefs and the concept of hidden emotion (HE), namely understanding the hidden emotions or feelings of others. The five ToM concepts were understood by children sequentially or gradually, namely, DD> DB> KA> FB> HE.

In addition to being connected to the child's ability to empathize with other people, obtaining ToM can also make children more accepted and popular among peer groups (Slaughter et al., 2002). Children who have the ToM ability also develop the ability to share imagination and joke with peers, negotiate, compromise, cooperate in play, and follow the rules of the game (Mar et al., 2010). Researchers also found the ability of ToM was positively related to social behaviors such as children like to give help to others. Realizing the important role of ToM in developing social skills in children, therefore many researchers investigate the factors that influence the acquisition of ToM (Mar et al., 2010).

The research results of Mar, Tacket, and Moore found that the acquisition of ToM is influenced by the socialization of narrative media (storybooks and films) of children aged 4-6 years (Mar et al., 2010). Narrative media are media in the form of stories about various kinds of social interactions such as conflict, misunderstanding, understanding, and resolution (Kinnebrock \& Bilandzic, 2006). These stories can make children connect with situations that describe the mental state of others such as feelings, beliefs, misunderstandings, different thoughts, and views that the characters in the story have (Ratner, 1998). When children watch children's story media is connected with various mental situations of characters so that the media story is thought to be able to help children understand the mental state of others (Guajardo \& Watson, 2002; Mishna et al., 2009).

Based on the research results of Mar, Tacket, and Moore, it is concluded that the movie is proven to support the acquisition of ToM. In recognition tests, researchers ask parents to choose a recognized film title from a list of films, the child's exposure to film media is based solely on the choice of parents on some titles in a given list. Parents' knowledge of some children's film titles cannot describe the child's exposure to narrative media (Mar et al., 2010; Black et al., 2003; Haswadi et al., 2018). According to Van Mierlo, the number of time children spends when using media is an important indicator in measuring exposure to the media. Therefore, this research will look at children's exposure to narrative media based on how long the children are exposed to narrative media, especially children's films (Van Mierlo, 2008).

Also, in previous studies, the researchers only tested the effect of narrative media exposure on overall ToM acquisition. In this study, the researcher wanted to know the effect of film exposure on the acquisition of each ToM concept, namely children's understanding of the concept of diverse desires, diverse beliefs, knowledge access, false belief, and hidden emotion. Currently, children's films have been shown on television because television is still an entertainment that is in great demand by the public, especially children. In this connection, the researcher wanted to know the effect of exposure to children's films on television on the acquisition of ToM in preschool-aged children in West Sumatra.

\section{Research Methods Participants}

Participants in this study were children aged 3-5 years because according to experts at the age of 3-5 years the child's 
ability to understand other people's mental states began to develop rapidly. Researchers also determined the criteria for child participants aged 3-5 years, namely attending Kindergarten. This procedure is carried out to obtain the same criteria as the same learning facilities. Besides, the selection of participants to attend kindergarten aims to make it easier for researchers to obtain information about children's development, for example, information on children's verbal abilities. Parental characteristics are determined based on an income of around Rp. 5,000,000. - IDR $10,000,000$. per month and a minimum of high school education. The determination of participants is based on school admission fees of between Rp. 3,000,000,. - IDR 4,000,000. This procedure is carried out based on the opinion of Pears and Moses which states that the socioeconomic status, demographics, and education of parents have a relationship with the acquisition of ToM (Pears \& Moses, 2003).

The next selection of participants was based on the participants' willingness to be involved in the research which was started through the informed consent that had been filled in by the parents. To obtain data on the development of ToM in children aged 3-5 years, researchers planned the number of male and female participants, namely 85 children. Participants were determined by conducting an initial survey of schools that matched the criteria. Researchers obtained information about schools that match the criteria through colleagues who live in the city. Researchers asked for children's biodata information from the school.

\section{Equipment and procedures}

ToM measurement uses the ToM scale by Wellman and Liu which has been adapted in Indonesian language and culture by Kuntoro et al. (2013), The ToM scale consists of five assignments given in the form of stories to see children's understanding of the concepts of diverse desire, diverse beliefs, knowledge access, false belief, and hidden emotion (Wellman et al., 2001). The five tasks of the ToM scale consist of control questions and target questions. Control questions aim to determine the extent to which children understand the storyline while target questions aim to measure children's understanding of each ToM concept. Understanding ToM can be seen from the accuracy of children's responses in answering target questions and control questions.

The children's exposure to movies on TV is obtained by distributing questionnaires to the parents of the child participants after completing the ToM test. The questionnaire is made in 2 versions, namely manual and google form. Some parents are willing to fill out questionnaires in manual form, some in the google form. The questions in the questionnaire include the number of children's movie titles on TV that children watch, how many times (frequency) children watch movies in 1 week, and how long (duration) children watch movies in 1 day. Data collection with the ToM scale was carried out in schools by first submitting a research permit issued by LP2M Padang State University to the school. Researchers submitted informed consent to parents through the school regarding the involvement of children and parents in the study. After obtaining the consent of the participants' parents, researchers can start the study.

Before conducting the research, the researcher had studied the ToM assignment procedure and practiced role play with 2 children who had the same characteristics as the study participants. This procedure aims to help researchers to become familiar with the proper ToM assignment procedure. Also, it is to find out whether the child recognizes the material used well and to find out the child's understanding of the story conveyed in the ToM assignment. In connection with the covid-19 pandemic, 19 teaching and learning activities in schools were eliminated. Researchers through the school asked parents to be willing to participate in research activities. The ToM experiment was carried out in schools by asking parents to take their children to school in turn. ToM experiments can be started at the second meeting. The researcher planned 4-5 participants who would be given the ToM assignment at each meeting. Thus the total number of meetings for 85 children is 17 meetings. Participants are given 5 ToM assignment scales gradually starting from diverse desires, diverse beliefs, knowledge access, false beliefs, and finally hidden emotions. Repetition of storytelling can be done twice if the child cannot answer the control questions. Meanwhile, the target question was not repeated if the child could not answer the question correctly. Children are given a reward in the form of biscuit wafers after completing the ToM experiment. The ToM experiment takes a maximum of 10 minutes per child. The film exposure questionnaire was measured by the researcher distributing the questionnaire to the parents (father or mother) of the participants. Questionnaires were distributed only to parents whose children had completed the ToM assignments. Parents can fill out the questionnaire at home / at school or online via the google form. Parents who filled out the questionnaire received a memento in the form of prayer beads/brooch. 


\section{Result}

Researchers tested the effect of exposure to children's films on TV on ToM processing in preschoolers using simple regression with the SPSS program. Based on the results of data analysis, it is known that exposure to children's films on TV has no significant effect on the acquisition of ToM with $\mathrm{R} 2=.030, \mathrm{p}>0.05$. Furthermore, the results of the analysis of the exposure test for children's films on TV on the acquisition of ToM can be seen through the following table:

Table 1

Multiple Regression Analysis The Effect of Children's Film Exposure on TV on ToM

\begin{tabular}{lccccc}
\hline Variable & $B$ & $S E B$ & $\beta$ & $t$ & $P$ \\
\hline Children's Film Exposure on TV & -0.141 & 0.89 & -0.172 & -1.592 & .115 \\
\hline
\end{tabular}

$\mathrm{R} 2=.030 \mathrm{~N}=85, \mathrm{p}>0.05)$

Based on Table 1, it is known that exposure to children's films on TV has an insignificant regression coefficient $(\beta=$ $-0.172, \mathrm{P}>0.05$ ). Thus $\mathrm{Ha}$ is rejected, meaning that exposure to children's films on TV does not have a significant effect on the acquisition of ToM in preschool children. This study also wanted to determine the effect of exposure to children's films on TV on each ToM concept consisting of Diverse Desires (DD), Diverse Beliefs (DB), Knowledge Access (KA), False Beliefs (FB), and Hidden Emotion (HE). Researchers used the SPSS program logistic regression statistical analysis because the ToM concepts were a dichotomous scale (true/false).

Table 2

Logistic Regression Analysis The Effect of Children's Film Exposure on TV on ToM Concept

\begin{tabular}{llllll}
\hline Variable & DD & DB & KA & FB & HE \\
\hline Children's Film Exposure on TV & $p=.942$ & $p=.475$ & $p=.695$ & $p=.024^{*}$ & $p=.343$
\end{tabular}

Note: ${ }^{*} \mathrm{p}<0.05$ Table 2 . shows that the exposure of children's movies on TV only has a significant effect on the concept of ToM false belief (FB). The results of logistic regression analysis of the effect of exposure to children's movies on TV on the FB concept can be seen in Table 3 below.

Table 3

The Influence of Children's Film Exposure on TV on the Acquisition of the FB Concept

\begin{tabular}{llllll}
\hline Variable & B & SE & Odd Ratio & Wald Statistic & P \\
\hline Children's Film Exposure on TV & -.472 & .208 & $.624^{*}$ & 5.130 & .024 \\
\hline
\end{tabular}

Note: ${ }^{*} p<0.05$ Based on Table 3 it can be explained that exposure to children's films on TV has a significant effect on the concept of FB. The probability of obtaining the ToM of children for understanding the concept of FB in children exposed to children's movies on TV is 0.624 times higher compared to children who are not exposed to children's films on TV.

\section{Conclusion}

This study answered the research question of whether exposure to children's films on TV affected the acquisition of ToM in preschool children. Based on the results of simple regression analysis, it was found that exposure to children's films on TV did not significantly affect the acquisition of ToM in preschool children. This study also looked at the effect of exposure to children's films on TV on the acquisition of each ToM concept with logistic regression analysis. The results of data analysis show that exposure to children's films on TV only has a significant effect on understanding the concept of FB. The results of this study indicate that exposure to children's films on TV is not one of the factors affecting the acquisition of ToM of preschoolers.

The results of this study are almost the same as the findings of Mar, Tacket, and Moore which show that TV shows do not affect the acquisition of ToM in preschoolers. The suspicion is that there is a commercial break on TV films that disturbs children's attention while watching movies on TV (Mar et al., 2010). According to Shrum, if the 
child's attention during watching is reduced, the information from the viewing will be more difficult for the child to absorb. Therefore, commercial breaks can hinder children's understanding of the mental state presented by TV shows, so that children's exposure to films on TV does not affect the ToM of preschoolers (Shrum, 2004).

Another factor that may influence this is that generally the films shown on TV are imported films that have cultural values that are different from the culture of children in Indonesia. It is suspected that the film stories on TV make it difficult for children to relate them to mental situations in daily life. Also, it is suspected that the film that children watch is the kind of film that does not tell much about mental situations, for example, the animated film angry bird/owl. Researchers say that narrative media (films) can support the acquisition of ToM if the stories contained therein describe a social context and contain many sentences that explain mental states (Mar et al., 2010).

The results of this study also show that other factors play a greater role in developing children's theory of mind acquisition, such as conversations between mothers and children, discussions between children and parents about television programs, and the existence of siblings (Rusli et al., 2020; Dyer et al., 2000; Ruffman et al., 2002; Nathanson et al., 2013). Based on the results of the logistic regression analysis test, shows that exposure to children's films on TV has a significant effect on the acquisition of false beliefs (FB). As expressed by experts, the film contains stories about various kinds of emotional conditions, desires, feelings experienced by the characters. As children experience the stories from the film, this can connect the children to their understanding of various mental situations including understanding the wrong beliefs of others. The acquisition of false beliefs is related to the ability to understand points of view and to empathize with others.

The limitation of this study is that the study does not look at how much information about mental situations is contained in children's films that are broadcast on TV. This is the researcher's conjecture as to why film exposure on tv does not affect ToM acquisition. This study did not explore children's understanding of social interactions from the stories in the films they watched. Besides, this study also did not look at the interaction between children and parents while watching movies on TV. Based on the explanation of the conclusions and discussions that have been described above, the researcher suggests that further research is related to the relationship between children's film exposure on TV and ToM, namely that the next researcher is expected to be able to dig up information about films that tell about mental situations. Further research also needs to look at the interaction between parents and children while watching TV which can play a role in obtaining ToM.

\section{References}

Astington, J. W., \& Jenkins, J. M. (1995). Theory of mind development and social understanding. Cognition \& Emotion, 9(2-3), 151-165.

Baron-Cohen, S., Leslie, A. M., \& Frith, U. (1985). Does the autistic child have a "theory of mind"?. Cognition, 2l(1), 37-46. https://doi.org/10.1016/0010-0277(85)90022-8

Black, R. E., Morris, S. S., \& Bryce, J. (2003). Where and why are 10 million children dying every year?. The lancet, 361(9376), 2226-2234. https://doi.org/10.1016/S0140-6736(03)13779-8

Bloom, P., \& German, T. P. (2000). Two reasons to abandon the false belief task as a test of theory of mind. Cognition, 77(1), B25-B31. https://doi.org/10.1016/S0010-0277(00)00096-2

Cutting, A. L., \& Dunn, J. (1999). Theory of mind, emotion understanding, language, and family background: Individual differences and interrelations. Child development, 70(4), 853-865.

Dyer, J. R., Shatz, M., \& Wellman, H. M. (2000). Young children's storybooks as a source of mental state information. Cognitive Development, 15(1), 17-37. https://doi.org/10.1016/S0885-2014(00)00017-4

Flavell, J. H.., \& Miller, P. H. (1998). Social cognition. In D. Kuhn and R. S. Siegler. Handbook of child psychology, Vol.2, Cognition, perception, and language, 5th ed, (pp. 851-898), New York.

Guajardo, N. R., \& Watson, A. C. (2002). Narrative discourse and theory of mind development. The Journal of Genetic Psychology, 163(3), 305-325.

Haswadi, M., Syarifudin, S., \& Rusdiawan, R. (2018). Children Phonological Acquisition for 3 to 5-YearOlds. International Journal of Linguistics, Literature and Culture, 4(1), 16-21.

Kinnebrock, S., \& Bilandzic, H. (2006). How to make a story work: Introducing the concept of narrativity into narrative persuasion.

Kuntoro, I. A., Saraswati, L., Peterson, C., \& Slaughter, V. (2013). Micro-cultural influences on theory of mind development: A comparative study of middle-class and pemulung children in Jakarta, Indonesia. International Journal of Behavioral Development, 37(3), 266-273.

Mar, R. A., Tackett, J. L., \& Moore, C. (2010). Exposure to media and theory-of-mind development in 
preschoolers. Cognitive Development, 25(1), 69-78. https://doi.org/10.1016/j.cogdev.2009.11.002

Marasabessy, N.B., \& Suhron, M. (2020). Stress Family Experience And Profiles Of Tumor Necrosis Factor Alpha And Interleukin-10 Of Nuaulu Tribe Community With Hunting Activity In Mesoendemic Area Of Malaria. Systematic Reviews in Pharmacy. SRP, 11(11), 1886-1891.

Mishna, F., Saini, M., \& Solomon, S. (2009). Ongoing and online: Children and youth's perceptions of cyber $\begin{array}{llll}\text { bullying. Children } \text { Ind } \quad \text { Youth } & \text { Rervices } & \text { Review, 31(12), } & \end{array}$ https://doi.org/10.1016/j.childyouth.2009.05.004

Nathanson, A. I., Sharp, M. L., Aladé, F., Rasmussen, E. E., \& Christy, K. (2013). The relation between television exposure and theory of mind among preschoolers. Journal of Communication, 63(6), 1088-1108.

Pears, K. C., \& Moses, L. J. (2003). Demographics, parenting, and theory of mind in preschool children. Social development, 12(1), 1-20.

Ratner, N. K., \& Olver, R. R. (1998). Reading a tale of deception, learning a theory of mind?. Early Childhood Research Quarterly, 13(2), 219-239. https://doi.org/10.1016/S0885-2006(99)80036-2

Ruffman, T., Slade, L., \& Crowe, E. (2002). The relation between children's and mothers' mental state language and theory-of-mind understanding. Child development, 73(3), 734-751.

Rusli, D. (2020). Pengaruh Gaya Pengasuhan Autonomy dan Conformity Terhadap Perolehan Theory-of-Mind pada Anak Prasekolah di Sumatera Barat. Jurnal RAP (Riset Aktual Psikologi Universitas Negeri Padang), 11(2), 113127.

Rusli, D., Kuntoro, I. A., Handayani, E., \& Arben, A. (2020). The influence of individualism and collectivism parenting on theory-of-mind acquisition in children aged 3-5. International Journal of Psychosocial Rehabilitation, 24(9), 3053-3063.

Shahaeian, A., Peterson, C. C., Slaughter, V., \& Wellman, H. M. (2011). Culture and the sequence of steps in theory of mind development. Developmental psychology, 47(5), 1239.

Shrum, L. J. (2004). The cognitive processes underlying cultivation effects are a function of whether the judgments are on-line or memory-based. Communications, 29(3), 327-344.

Slaughter, V., Dennis, M. J., \& Pritchard, M. (2002). Theory of mind and peer acceptance in preschool children. British journal of developmental psychology, 20(4), 545-564.

Suhron M, Zainiyah Z., How Were Stress Family and INSR (Insulin Receptor) Expression in Polycystic Ovary Syndrome (PCOS) Insulin Resistant in Madurese Tribe?: Indonesia. Systematic Reviews in Pharmacy. Vol 12(1), pp. 170-175. 2020

Suhron, M. (2016). Asuhan keperawatan konsep diri: Self esteem.

Suhron, M. (2017). Asuhan keperawatan jiwa konsep self esteem. Jakarta: Mitra Wacana Media.

Suhron, M., \& Amir, F. (2018). Reduce Violent Behavior Schizophrenia: A New Approach Using LT (Laughing Therapy) and DRT (Deep Relaxation Therapy). Indian Journal of Public Health Research \& Development, 9(8).

Suhron, M., Sulaihah, S., \& Yusuf, A. H. (2017). Model of Potential Strengthening and Family Roles in Improving Family Members for ODGJ Adaptability. In Proceeding of The 2nd International Symposium of Public Health (pp. 344-351). Faculty of Public Health Universitas Airlangga.

Suhron, M., Yusuf, A., \& Subarniati, R. (2019). Assessment of Stress Reactions and Identification of Family Experiences in Primary Care Post Restrain Schizophrenia in East Java Indonesia. Mix Method: Sequential Explanatory. Indian Journal of Public Health Research \& Development, 10(12).

Suhron, M., Yusuf, A., Subarniati, R., Amir, F., \& Zainiyah, Z. (2020). How does forgiveness therapy versus emotion-focused therapy reduce violent behavior schizophrenia post restrain at East Java, Indonesia?. International Journal of Public Health, 9(4), 314-319.

Van Mierlo, J. (2008). How to measure television exposure from a contents-received point of view? The use of different measures of television exposure in cultivation research.

Wellman, H. M., \& Liu, D. (2004). Scaling of theory-of-mind tasks. Child development, 75(2), 523-541.

Wellman, H. M., Cross, D., \& Watson, J. (2001). Meta-analysis of theory-of-mind development: The truth about false belief. Child development, 72(3), 655-684.

Wimmer, H., \& Perner, J. (1983). Beliefs about beliefs: Representation and constraining function of wrong beliefs in young children's understanding of deception. Cognition, 13(1), 103-128. https://doi.org/10.1016/00100277(83)90004-5

Yusuf, A., Suhron, M., \& Subarniati, R. (2019). Assessment of the Kempe Family Stress Inventory in self-care postrestrain schizophrenia. International Journal of Public Health Science (IJPHS), 8(2), 55-59. 